\title{
Cannabidiol lowers incidence of diabetes in non-obese diabetic mice
}

\author{
L. WEISS ${ }^{1}$, M. ZEIRA ${ }^{1}$, S. REICH ${ }^{1}$, M. HAR-NOY ${ }^{1}$, R. MECHOULAM ${ }^{2}$, S. SLAVIN ${ }^{1}, \&$ \\ R. GALLILY ${ }^{3}$ \\ ${ }^{1}$ Department of Bone Marrow Transplantation E Cancer Immunotherapy, Hadassah University Hospital, POB 12000, \\ Ferusalem 91120, Israel, ${ }^{2}$ Department of Medical Chemistry and Natural Products, Hebrew University Medical Faculty, \\ Ferusalem 91120, Israel, and ${ }^{3}$ Department of Immunology, Hebrew University Medical Faculty, Ferusalem 91120, Israel
}

(Received 25 fanuary 2005; in revised form 14 September 2005)

\begin{abstract}
Cannabidinoids are components of the Cannabis sativa (marijuana) plant that have been shown capable of suppressing inflammation and various aspects of cell-mediated immunity. Cannabidiol (CBD), a non-psychoactive cannabidinoid has been previously shown by us to suppress cell-mediated autoimmune joint destruction in an animal model of rheumatoid arthritis. We now report that CBD treatment significantly reduces the incidence of diabetes in NOD mice from an incidence of $86 \%$ in non-treated control mice to an incidence of 30\% in CBD-treated mice. CBD treatment also resulted in the significant reduction of plasma levels of the pro-inflammatory cytokines, IFN- $\gamma$ and TNF- $\alpha$. Th1-associated cytokine production of in vitro activated T-cells and peritoneal macrophages was also significantly reduced in CBD-treated mice, whereas production of the Th2-associated cytokines, IL-4 and IL-10, was increased when compared to untreated control mice. Histological examination of the pancreatic islets of CBD-treated mice revealed significantly reduced insulitis. Our results indicate that CBD can inhibit and delay destructive insulitis and inflammatory Th1-associated cytokine production in NOD mice resulting in a decreased incidence of diabetes possibly through an immunomodulatory mechanism shifting the immune response from Th1 to Th2 dominance.
\end{abstract}

Keywords: Type 1 diabetes, cannabidiol, Th1/Th2 biology, IFN- $\gamma$

\section{Introduction}

The Cannabis sativa (marijuana) plant contains components that are termed cannabinoids. Cannabinoids are known to have a variety of potential therapeutic effects which include analgesic, antiinflammatory and immunosuppressive properties $[1,2]$. The major psychoactive cannabinoid is Delta 9-tetrahydrocannabinol (THC) whose effects are mediated through the $\mathrm{CB} 1$ and the CB2 subtypes of cannabinoid receptors found in the brain and lymphoid tissues [3]. THC has potent immunosuppressive properties and can modulate Th1/Th2 balance by enhancing Th2 and suppressing Th1 immune responses [4-7]. However, the psychoactive effects of THC limit its consideration as a therapy for Th1-mediated autoimmune diseases.

Cannabidiol (CBD), on the other hand, is a cannabinoid that has potential for clinical research and therapeutic use because it does not produce psychoactive effects due to a low affinity for the CB1 and CB2 receptors $[8,9]$ and is also well tolerated without side effects when chronically administered to humans $[10,11]$. However, the anti-inflammatory, immunosuppressive and Th1/Th2 altering effects of CBD have not been as well characterized as those of THC.

CBD has previously been shown to be better than THC in inhibiting pro-inflammatory IL-1, TNF- $\alpha$, and IFN- $\gamma$ cytokine release by peripheral blood

Correspondence: S. Slavin, Department of Bone Marrow Transplantation \& Cancer Immunotherapy, Hadassah University Hospital, POB 12000, Jerusalem 91120, Israel. Tel: 9722677 7270. Fax: 9722642 2731. E-mail: slavin@hadassah.org.il 
mononuclear cells [12]. We previously demonstrated that $\mathrm{CBD}$ was effective in suppressing progression of autoimmune joint destruction in the collagen-induced arthritis animal model of rheumatoid arthritis, a Th1-mediated disease [13]. The anti-autoimmune effects of CBD were associated with reduction in synovial cell $\mathrm{TNF}-\alpha$ production, inhibition of reactive oxygen release from zymosan-stimulated neutrophils, suppression of macrophage nitric oxide (NO) production and suppression of joint-specific T-cell proliferation and IFN- $\gamma$ production.

CBD has also recently been shown to have potent anti-inflammatory effects in rat paw carrageeninduced inflammation [14] associated with reduction in prostaglandin E2 (PGE2), tissue cyclooxygenase (COX) activity, and production of oxygen-derived free radicals and production of NO.

Since CBD has been shown to inhibit production of IL- $1 \beta, \mathrm{TNF}-\alpha$ and IFN- $\gamma$, as well as the inflammatory mediators NO, COX and PGE2 and these factors are known to be involved in the pathway of autoimmune islet cell destruction leading to diabetes, we decided to test the anti-autoimmune effects of CBD in the NOD mouse model of type 1 diabetes.

The aim of this study was to determine if CBD could prevent or delay diabetes occurrence in the spontaneous NOD mouse model of type 1 diabetes. We examined the effect of CBD on the development of diabetes in untreated and treated female NOD mice by assaying glucose levels in urine and analyzing insulitis and beta cell integrity in histopathological sections of the pancreases.

We report that CBD significantly inhibited insulitis, beta cell destruction and the occurrence of overt diabetes in the NOD mice. In addition, we found that CBD treatment resulted in suppressed production of the Th1-associated cytokines, IL-12, IFN- $\gamma$ and $\mathrm{TNF}-\alpha$, and enhanced production of the Th2associated cytokines, IL- 4 and IL-10, suggesting a possible deviation from destructive Th1 immunity to protective Th2 immunity.

\section{Material and methods}

Mice

Female non-obese diabetic NOD/LtJ mice, 6-12week-old, were obtained from Harlan, Israel. Mice were fed standard laboratory animal chow ad libitum and were kept in a specific pathogen free (SPF) animal housing facility. The study was conducted in compliance with international laws on animal experimentation and "Principles of Laboratory Animal Care" (NIH publication No. 86-23, revised 1985) were followed. The study was approved by the Ethical Committee of the Hebrew University Medical School.

\section{$C B D$}

CBD was extracted from cannabis resin (hashish) as previously reported [15]. For in vivo injection, CBD was first dissolved in ethanol and then Cremophor EL (Sigma) was added at a 1:1 ratio. This solution was then further diluted in saline so that the final solution was ethanol/Cremophor/saline (1:1:18).

\section{Experimental design}

CBD was administered i.p. at a dose of $5 \mathrm{mg} / \mathrm{kg} /$ day. Ten to twenty injections ( 5 times a week) were administered to 6-12-week-old female NOD mice. Two groups of mice served as controls, one group received the Cremophor/ethanol/saline vehicle only and the other group remained untreated. The level of urine glucose was assayed once or twice a week by test strips (Medi-Test Combi 9 Macherey-Nagel, Duren) and was considered positive after the appearance of glucosuria in at least two consecutive determinations.

\section{Peritoneal macrophage culture}

Peritoneal lavages from each untreated and CBDtreated mouse were centrifuged and the peritoneal macrophage pellets were resuspended and plated in 24well plates for $2 \mathrm{~h}$. The wells were washed to remove non-adherent cells and fresh DMEM with 10\% FCS supplemented with $1 \mu \mathrm{g} / \mathrm{ml}$ LPS (W.E.Coli type 055:B5 Difco-Bacto Labs, Detroit, MI, USA) was added to wells for further over night incubation. Harvested supernatants were centrifuged to remove any cells and stored at $-80^{\circ} \mathrm{C}$ until assayed for cytokines.

\section{Splenic lymphocyte culture}

Spleen cells from each untreated and CBD-treated mouse were washed in PBS, resuspended in RPMI medium supplemented with $10 \%$ Fetal Bovine Serum, $100 \mathrm{U} / \mathrm{ml}$ penicillin, $100 \mu \mathrm{g} / \mathrm{ml}$ streptomycin and $2 \mathrm{mM} \mathrm{L}$-glutamine and dispensed into 24 -well plates (Greiner Labs, Germany) at $2 \times 10^{6}$ cells $/ \mathrm{ml}$ medium per well. Cells were stimulated with $2.5 \mu \mathrm{g} / \mathrm{ml} \mathrm{ConA}$ (Sigma, St. Louis MI, USA) and cultured at $37^{\circ} \mathrm{C}$ in a $5 \% \mathrm{CO}_{2}$ humidified incubator. Supernatants were harvested after $48 \mathrm{~h}$ incubations, cleared by centrifugation and stored at $-80^{\circ} \mathrm{C}$ until assayed for cytokines.

\section{Cytokine assay}

Levels of cytokines in the plasma and in the supernatants of splenic lymphocytes and peritoneal macrophages of the mice were assayed by "sandwich" ELISA technique. ELISA reagents were purchased as Opt. EIA Cytokine ELISA sets from BD Biosciences (San Diego, CA, USA) and were used according to the manufacturer's protocol as previously described [16]. 


\section{Histopathology}

Pancreatic tissue was fixed in $4 \%$ buffered formalin and was embedded in paraffin, and $5-\mu \mathrm{m}$ sections were stained with hematoxylin and eosin. Sections containing a total of more than 17 islets from each pancreas were screened and scored by two independent observers and were graded according to the following scores: intact islets; partially infiltrated islets and peri-infiltrated islets; totally infiltrated islets; and destroyed islets.

\section{Results \\ $C B D$ reduces diabetes disease incidence in NOD mice}

To determine the ability of CBD to suppress the cumulative incidence or delay the onset of diabetes in NOD mice, we chose to treat female animals that already had insulitis, but did not have overt disease. This status was chosen to approximate the immunological status of a pre-type 1 diabetic human patient. In NOD mice, insulitis begins at 4-5 weeks of age and is present in $100 \%$ of females $[17,18]$. Therefore, we used only female mice that were a minimum of 6 weeks old.

Disease onset in female NOD mice had been reported to begin at $8-10$ weeks of age with a cumulative frequency of $70-90 \%[17,18]$. However, many differences exist between NOD mouse colonies [19]. In our colony, the female NOD mice developed overt diabetes at a median of 14 weeks, therefore, CBD treatments were administered to mice that were up to 12 weeks of age. All mice were normoglycemic at the time of initiation of experiments.

Female NOD mice 6-12 weeks of age were treated with 10-20 i.p. injections of $5 \mathrm{mg} / \mathrm{kg} \mathrm{CBD}$. There was no difference in the treatment outcome as a function of the number of CBD injections, therefore, the results of all experiments were pooled for statistical analysis. These results are summarized in Figure 1 and Table I.

We show that $86 \%$ of the untreated control mice developed diabetes in a median of 14 weeks (range of 10-20 weeks). The CBD-treated mice demonstrated a significant reduction in disease incidence compared to the untreated mice with only $30 \%$ of CBD-treated mice developing disease $(p=0.00003)$. Further, the fraction of mice that developed disease in the CBDtreated group (6 of 20 mice) had a delayed onset of disease and this delay was significant when compared to the untreated control group (20 week median onset in the CBD-treated group compared to 14 week median onset in the control group, $p=0.0001$ ).

In another experiment, CBD-treated mice were observed for diabetes incidence at 26 weeks. The control mice (5 mice) all developed diabetes at a median of 17 weeks (range 15-20 weeks) while 3 of 5 $(60 \%)$ CBD-treated mice remained diabetes-free at 26 weeks.

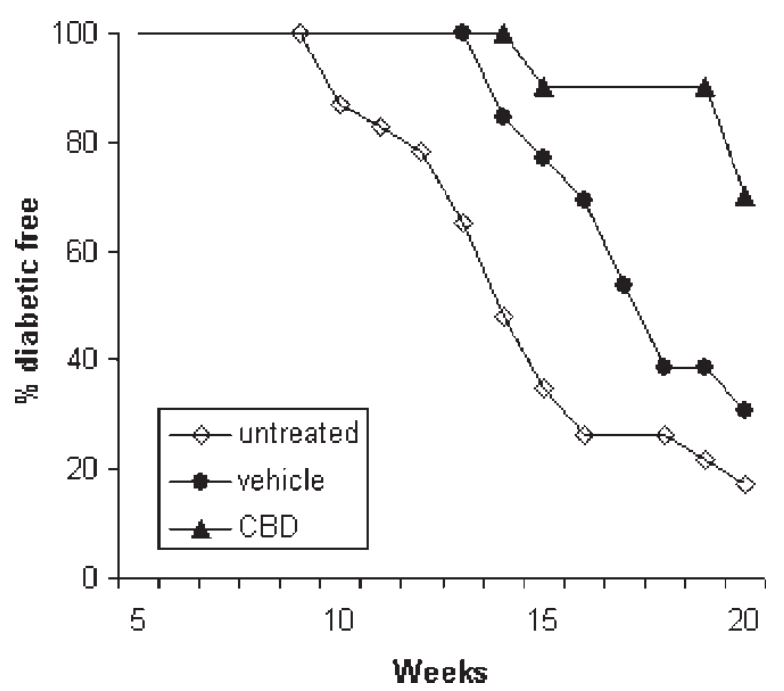

Figure 1. Incidence of diabetes in NOD mice treated with $5 \mathrm{mg} / \mathrm{kg}$ CBD i.p., vehicle control and untreated mice. The incidence of diabetes in the CBD treated group is significantly less when compared to both the control and vehicle groups.

CBD is a hydrophobic molecule and poorly soluble in water, therefore, it was solubilized in Cremophor EL (a polyethoxylated castor oil) and ethanol for injection (vehicle). To determine if the vehicle would have an effect independent of CBD, we evaluated a group of mice treated with vehicle alone. Vehicletreated mice had a disease incidence of $69 \%$, which was lower, but not significantly different than, the disease incidence in the untreated mice. However, the time to disease onset in the fraction of vehicle-treated mice that developed disease was significantly extended compared to the time of onset in untreated mice (median of 17.5 weeks in vehicle-treated mice compared to a median of 14 weeks in control mice, $p=0.05)$.

The incidence of disease in the CBD-treated group $(30 \%)$ was significantly lower than both the untreated control $(86 \%, p=0.00003)$ and the vehicle-treated control $(69 \%, p=0.009)$. Time to the onset of disease in the fraction of mice that developed diabetes in the CBD-treated mice (median 20 weeks) was also significantly extended when compared to both the time to onset in the untreated control group (median 14 weeks) and the vehicle-treated group (17.5 weeks).

These data demonstrate the ability of CBD treatment to suppress the cumulative incidence and delay the onset of diabetes in NOD mice.

Plasma levels of IFN- $\boldsymbol{\gamma}$ and $T N F-\boldsymbol{\alpha}$ are reduced in CBDtreated mice

NOD mice have high levels of IFN- $\gamma$ and $T N F-\alpha$ secretion [20] and increased IFN- $\gamma$ levels are correlated with islet destruction and development of diabetes [21]. We, therefore, determined whether CBD had an effect on plasma levels of these inflammatory 
Table I. Occurrence of diabetes in CBD-treated NOD mice.

\begin{tabular}{|c|c|c|c|c|c|c|}
\hline Treatment & $\begin{array}{l}\text { No. of mice with } \\
\text { overt diabetes }\end{array}$ & $\begin{array}{l}\text { Median time to diabetes } \\
\text { incidence (range) in weeks }\end{array}$ & $p$ value ${ }^{\star}$ & $\begin{array}{l}\text { Total no. of mice } \\
\text { in group }\end{array}$ & $\%$ Diabetic mice & $p$ value $^{\dagger}$ \\
\hline Untreated & 19 & $14(10-20)$ & 0.05 & 22 & 86 & \\
\hline Vehicle & 9 & $17.5(14-20)$ & $0.0001 \ddagger$ & 13 & 69 & N.S. \\
\hline CBD & 6 & $20(15-20)$ & 0.008 & 20 & 30 & $P<0.05^{\S}$ \\
\hline
\end{tabular}

Cumulative appearance of diabetes in female NOD mice treated with $5 \mathrm{mg} / \mathrm{kg}$ CBD.

* Significance of delay in disease onset evaluated by Kaplan-Meier log bank Statistics.

¥CBD-treated vs. untreated.

" CBD-treated vs vehicle.

N.S. $=$ Non-significant.

† Significance of disease incidence evaluated by Student's $t$-test.

${ }^{\S}$ Significant when CBD treated group compared to both untreated and vehicle-treated.

cytokines. Both cytokine levels were significantly reduced in the CBD-treated mice (Table II).

We found that IFN- $\gamma$ levels in plasma of treated mice were $72 \%$ lower than the levels in the vehicle treated mice $(p<0.01)$ and $79 \%$ lower than the levels of untreated diabetic mice $(p<0.01)$. The levels of TNF- $\alpha$ in the plasma of treated mice were $77 \%$ lower than the vehicle treated and untreated control groups $(p<0.05)$. These results demonstrate a suppression of inflammatory cytokine levels in the plasma of CBDtreated mice compared to untreated and vehicletreated control groups.

\section{Shift in Th1/Th2 cytokine balance in activated splenocytes} and peritoneal macrophages

Diabetes is correlated with an altered balance of Th1/Th2 cytokines with an excess of Th1 cytokines and lack of Th2 cytokines [22-24]. We, therefore, investigated the effect of CBD on Th1 (IFN- $\gamma$, IL-12 and TNF- $\alpha$ ) and Th2 (IL-4 and IL-10) cytokine production in in vitro activated splenocytes and peritoneal macrophages. Analysis of these responses revealed a general shift towards production of Th2 cytokines in CBD-treated mice.

Splenocytes from each of the CBD-treated and vehicle-treated (control) NOD mice were polyclonally activated by cultivation for $48 \mathrm{~h}$ with ConA. Levels of IL- 4 and IFN- $\gamma$ produced by the splenocytes were assayed. The results are shown in Table III. We found a profound (99\%) suppression of IFN- $\gamma$ in CBDtreated mice, while the amount of IL- 4 production was increased by $41 \%$. These effects were statistically significant $(p<0.05)$.

The levels of IL-10, IL-12 and TNF- $\alpha$ cytokines produced by LPS-activated peritoneal macrophages were also modulated by CBD treatment of NOD mice. The decrease in the CBD treated mice of the pro-inflammatory cytokines IL-12 (by $74 \%$ ) and TNF- $\alpha$ (by 77\%) was significant compared to the control $(p<0.05)$, whereas IL-10, which inhibits the expression of the above pro-inflammatory cytokines was remarkably increased by greater than 5 -fold $(p<0.05)$ in macrophages from CBD treated mice. The levels of IL-10 were also elevated in unstimulated spleen cell supernatants from CBD-treated mice $(10 \mathrm{pg} / \mathrm{ml} \mathrm{IL}-10$ in the CBD-treated group compared to $0.5 \mathrm{pg} / \mathrm{ml}$ in the vehicle control).

Overall, these results indicate that CBD therapy induced a Th2-enriched environment in the periphery of NOD-mice.

\section{CBD therapy prevents insulitis development}

To test the therapeutic effect of CBD on the progression of insulitis, tissue sections of CBD-treated mice and control groups ( 3 mice from each group) were examined for the presence of infiltrating cells

Table II. Suppression of IFN- $\gamma$ and TNF- $\alpha$ levels in plasma of CBD-treated NOD mice.

\begin{tabular}{lccc}
\hline & \multicolumn{2}{c}{ IFN- $\gamma(\mathrm{pg} / \mathrm{ml})$} & \multicolumn{2}{c}{ TNF- $\alpha$} \\
\cline { 2 - 3 } & \multicolumn{2}{c}{ Average \pm SE } & Average \pm SE \\
\cline { 2 - 4 } Treatment of NOD mice & 13 weeks & 17 weeks & 20 weeks \\
\hline CBD & $43 \pm 10^{\star}$ & $10 \pm 4^{\star}$ & $6.7 \pm 0.88 \dagger$ \\
Vehicle & $94 \pm 21$ & $68 \pm 12$ & $29 \pm 14.1$ \\
Untreated diabetic & $100 \pm 22$ & $118 \pm 42$ & N.D. \\
\hline
\end{tabular}

IFN- $\gamma$ levels in plasma of female NOD mice untreated and treated with CBD at $13(n=5)$ and $17(n=10)$ weeks of age correspondingly. TNF- $\alpha$ levels in plasma of CBD treated and vehicle treated mice at 20 weeks of age $(n=3)$. N.D. $=$ not done.

* Significant difference $p<0.01$ of CBD vs vehicle and vs untreated control by the Kaplan-Meier statistics at both 13 weeks and 17 weeks.

${ }^{\dagger}$ Differences between experimental and control values and between experimental and vehicle were analyzed for significance $(p \leq 0.05)$ by one-tail distribution-free Mann-Whitney $U$-test. 


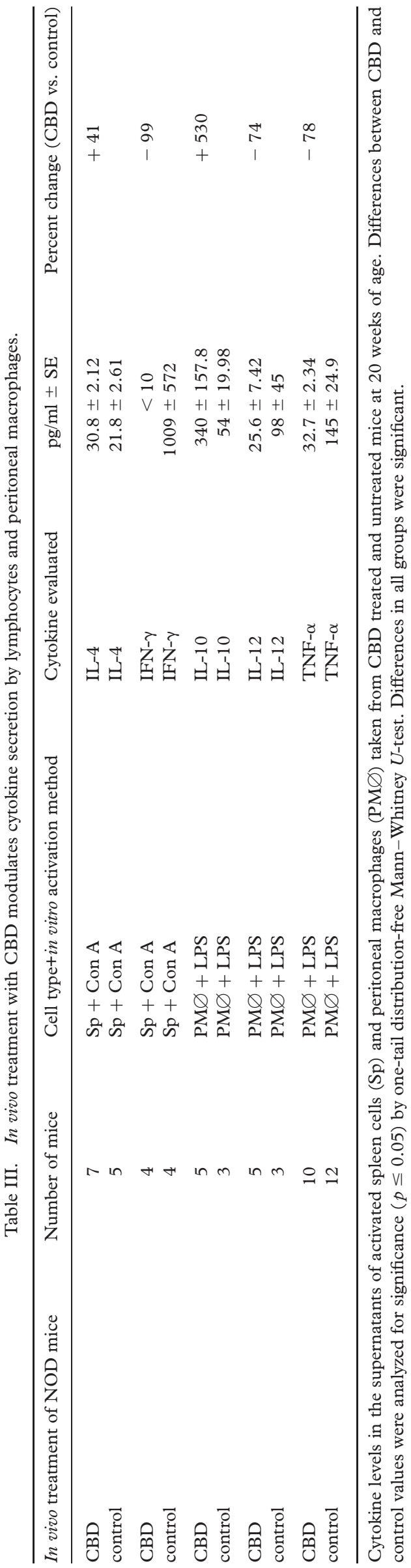

at 20 weeks of age. Histological examination revealed a reduction in the degree and severity of insulitis in CBD-treated mice compared to controls (Table IV). Representative islets from each group are shown in Figure 2.

Intact and partially infiltrated islets were observed in $87 \%$ of the CBD-treated mice, whereas only $4 \%$ and $15 \%$ were detected in the untreated and vehicletreated control mice, respectively. Only one islet out of 54 analyzed was fully destroyed in CBD-treated mice, compared to $21 \%$ and $51 \%$ of the islets in the vehicle-treated and untreated control mice, respectively.

These results suggest that CBD-treatment inhibited the progression to destructive insulitis. This data together with the cytokine data is indicative of a Th2 response that suppressed the beta cell destruction in the pancreas, since peri-insulitis has previously been associated with $\mathrm{Th} 2$ responses $[25,26]$.

\section{Discussion}

$\mathrm{CBD}$ is a non-psychoactive component of marijuana that possesses anti-inflammatory and immunosuppressive properties. Here we demonstrate the ability of $\mathrm{CBD}$ to significantly reduce the occurrence and delay the onset of overt diabetes in female NOD mice. NOD mice present with a clinical and immunological course very similar to human type 1 diabetes $[27,28]$. Therefore, these results raise the question of whether CBD could have a role in prevention of human type 1 diabetes.

The answer to this question will likely depend upon the further elucidation of the mechanism(s) of the anti-autoimmune properties of CBD. Specifically, the determination of whether CBD is acting as a nonspecific immunosuppressive agent or, alternatively (or in addition) acting through a mechanism of Th1/Th2 immune deviation. The present study suggests that CBD treatment may function by stimulating a protective Th2 immune response in NOD mice. This is demonstrated by a significant reduction in diabetes incidence in CBD-treated mice with a shift in regulatory cytokine production in the periphery from Th1-to Th2-biased.

Non-specific immunosuppressive activity would not be as desirable a mechanism for diabetes prevention as would be an immunomodulatory mechanism. Many non-specific immunosuppressive drugs have been shown to prevent diabetes in NOD mice [29], but such therapies have not been as successful in the clinic. The immunosuppressive drug cyclosporine, for example, has been administered to children with new-onset diabetes [30]. While cyclosporine-treated patients were shown to be more likely to be in remission after one year than non-treated controls, this difference was no longer significant at 2 years [31]. The limited efficacy of this approach combined 
Table IV. Inhibition of insulitis by CBD.

\begin{tabular}{lccccc}
\hline Treatment & No. of scored islets & Intact islets & Partially infiltrated islets/peri-insulitis & Totally infiltrated islets & Fully destroyed islets \\
\hline CBD & 54 & 26 & 21 & 6 & 1 \\
Vehicle & 52 & 0 & 2 & 29 & 21 \\
Untreated & 73 & 4 & 7 & 11 & 51 \\
\hline
\end{tabular}

Histological analysis of pancreas tissue (fixed in $4 \%$ buffered formalin) from mice treated with CBD, vehicle control and untreated control. Islets were scored according to the degree of mononuclear cell infiltration and islet integrity.

with safety concerns have limited the acceptance of cyclosporine therapy as a preventive treatment for diabetes.

A mechanism of non-specific immunosuppression requires lifelong treatment which poses substantial potential risks, including possible enhanced susceptibility to lethal opportunistic infection and increased risk of malignancy. While the long-term consequences of diabetes include blindness, renal failure and increased susceptibility to heart disease, these complications can be reduced with intensive insulin therapy aimed at normalizing glucose levels [32]. Therefore, the long-term safety of CBD as a nonspecific immunosuppressive therapy for diabetes would have to be carefully evaluated prior to use in humans and before such a therapy could be accepted as a preventive therapy for diabetes.
On the other hand, if CBD is acting as an immunomodulating therapy causing the deviation of the islet-specific immune response from $\mathrm{Th} 1$ to $\mathrm{Th} 2$, this might enable CBD to be used to prevent diabetes in early on-set patients prior to complete beta cell destruction or even possibly in high risk individuals. Once the autoimmune response is deviated from a destructive Th1 response to a protective Th2 response, presumably no additional CBD therapy would be necessary to maintain tolerance, therefore, reducing the concern regarding long-term safety issues.

The evidence presented herein is suggestive of an immunomodulatory effect of CBD on the clinical course of diabetes induction in NOD mice, possibly through an alteration of macrophage function. Cytokines from macrophages and other innate
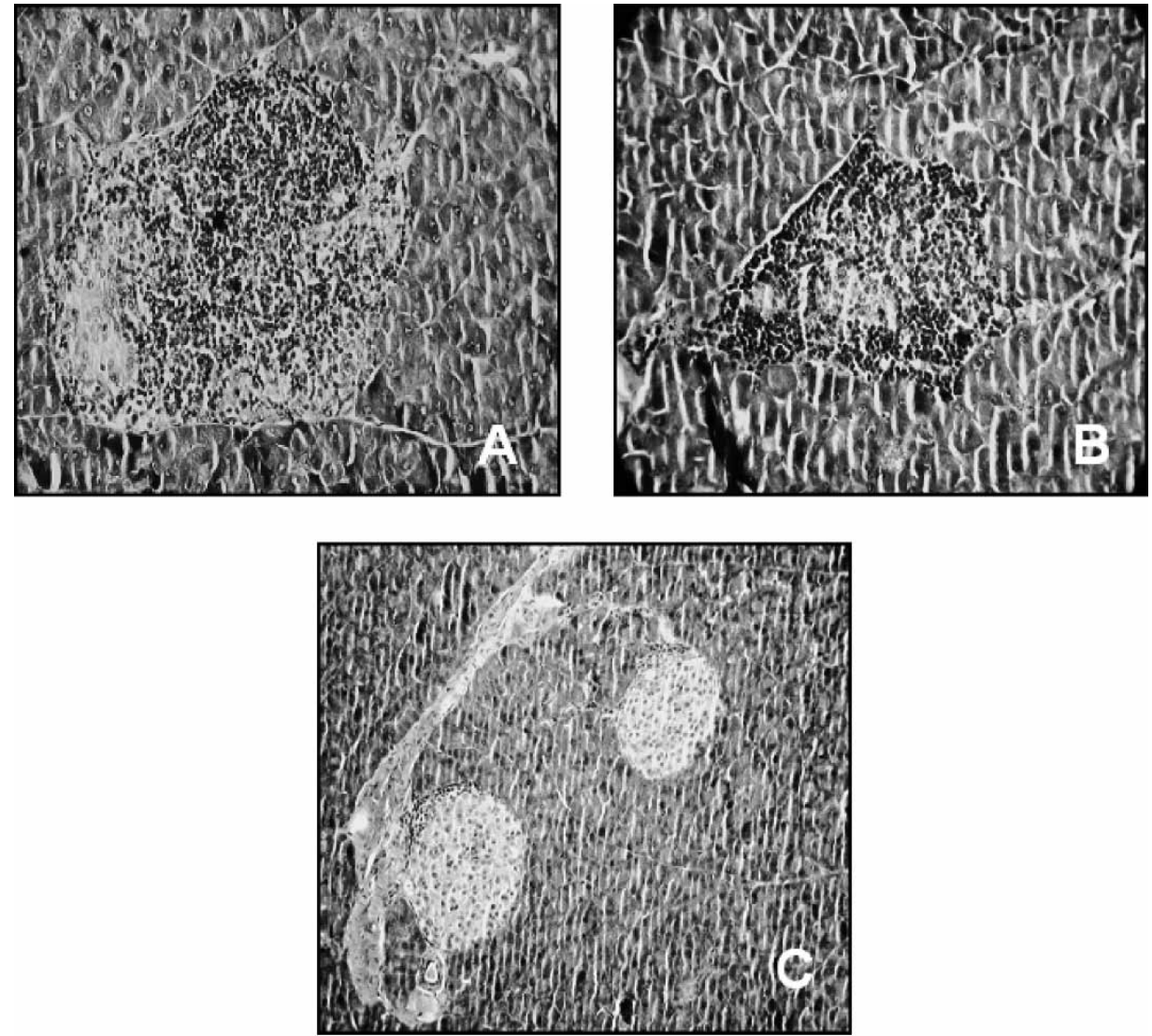

Figure 2. Representative histology of Hematoxylin-Eosin stained pancreases from (A) untreated control mice, mag. $\mathrm{x} 800$, (B) vehicletreated mice, mag. x 800, and (C) CBD-treated mice, mag. x 200. 
immune cells have a critical immunomodulatory role in skewing the adaptive immune response to either Th1 or Th2 [33]. In NOD mice, macrophages are critical for establishing Th1 autoimmunity, as depletion of macrophages leads to a shift from a Th1 to a Th2 immune response and a reduction in islet cell destruction [34]. Administration of IL-12, a macrophage derived cytokine, to macrophage-depleted NOD mice, on the other hand, initiates disease [34]. Therefore, CBD may have an immunomodulating effect through the suppression of macrophage inflammatory cytokine production.

Here we demonstrate that CBD significantly reduced macrophage IL-12 production and that plasma IFN- $\gamma$ levels were also significantly reduced. IL-12 is a key cytokine for skewing the development of adaptive immune responses. IL-12 induces the differentiation of Th1 cells and the production of IFN- $\gamma$ [35]. IFN- $\gamma$ in turn potentates the production of IL-12 [36]. Th1 cytokines, such as IFN- $\gamma$, also activate cytotoxic T-cells and stimulate macrophages to produce pro-inflammatory cytokines (i.e. $\mathrm{TNF}-\alpha$, IL-1, and IL-6) and nitrogen free radicals (e.g. NO) which all correlate with islet beta cell destruction [37]. Therefore, CBD suppression of macrophage IL-12 production could inhibit Th1-mediated autoimmunity.

We previously showed that CBD could block progressive autoimmune arthritis and that treated mice had significantly suppressed $\mathrm{TNF}-\alpha$ production [13]. Here we again show that CBD caused a significant reduction in $\mathrm{TNF}-\alpha$ production. AntiTNF therapy is widely used for treatment of autoimmune diseases such as rheumatoid arthritis, Crohn's disease, ankylosing spondylitis, and psoriatic arthritis. TNF- $\alpha$ levels are elevated in the serum of diabetic patients [38] and anti-TNF therapy can prevent diabetes in NOD mice [39]. Therefore, this is another potential therapeutic mechanism for CBD in the clinic.

The alterations in regulatory cytokines in CBDtreated mice also had an effect on regulatory cytokine production from T-cells. Activated splenocytes from the CBD-treated NOD mice were found to produce dramatically reduced levels of IFN- $\gamma$ and increased levels of IL-4. These results indicate a shift in the regulatory cytokine environment of the treated mice from an environment supportive of development of Th1 immunity to an environment supportive of Th2 immunity. However, it is not clear whether the alterations in cytokine production we demonstrate is the mechanism of disease suppression or is manifested as a consequence of the suppression.

The increased IL- 4 levels and reduced IFN- $\gamma$ levels in CBD-treated mice would enable the steering of an islet-specific immune response to Th2. It has been proposed that type 1 diabetes is the consequence of a progressive destruction of pancreatic beta cells mediated by an imbalance between effector Th1 and regulatory Th2 cell function [40], where Th1 immunity plays a critical role in the development of diabetes and where $\mathrm{Th} 2$ immunity may be protective [41,42].

Here we show that cells from CBD-treated mice produced in vitro enhanced IL- 4 and IL-10 cytokine production and such cytokine alterations correlated with disease suppression. Several reports support that immunological interventions, which enhance Th2 immune responses in NOD mice are protective against disease. For example, treatment of NOD mice with IL-4, a Th2 cytokine, prevents overt diabetes [43-45] and local expression of IL-4 in pancreatic beta cells in transgenic mice inhibits insulitis [46]. IL-10, a Th2 associated cytokine, is correlated with protection [46] and IL-4 and IL-10, together inhibit diabetes by suppressing Th1 cytokine production in islet grafts [47].

While our data shows that the regulatory cytokine environment was altered in CBD-treated mice, this study did not address the question of whether a Th1/Th2 shift occurred in the islet antigen-specific adaptive immune response, and if such a shift occurred, whether this shift provides long-term protection from disease without further intervention. This additional information will be critical in determining the immunomodulatory role of CBD and will be the subject of further investigation.

It is possible that the inevitable autoimmune response to islet antigens in NOD mice could be skewed to Th2 bias under the influence of a local cytokine milieu enhanced in IL-4 and reduced in IFN$\gamma$ and IL-12 as we demonstrate occurs after treatment with CBD. It is also possible that an islet-specific immune response developing under Th2-steering conditions could lead to a protective Th2 insulitis, rather than a destructive Th1 insulitis leading to diabetes [48]. In support of this possible mechanism, previous studies have demonstrated that an established insulin-specific autoimmune response in NOD mice that is highly Th1-biased [49] can be diverted with immunotherapy to a dominant Th2 immune response [50]. This suggests that an immunomodulatory therapy might be able to prevent diabetes through a mechanism of Th1/Th2 deviation even after the establishment of disease.

Most patients at onset of diabetes have approximately $10 \%$ of beta cells remaining and these islets remain functional as evidenced by residual c-peptide secretion. Approximately $50 \%$ of patients diagnosed with type 1 diabetes will enter a "honeymoon" remission phase of diabetes and remain insulin independent within the first year of diagnosis. Assuming these patients have sufficient residual beta cells to maintain normoglycemia and insulin independence, they will be candidates for immunomodulation therapy. 
CBD is non-psychoactive and has anti-inflammatory and anti-autoimmune properties. The results of the present study provide further evidence of the anti-autoimmune effects of CBD. The data presented herein suggests that CBD-treatment inhibits diabetes by induction of regulatory $\mathrm{Th} 2$ responses. This possible immunomodulatory effect of CBD is an interesting focus for further investigation. Confirmation of such a mechanism may lead to the clinical application of this agent in the prevention of type 1 diabetes, as well as possibly in other Th1-mediated autoimmune diseases.

\section{Acknowledgements}

We wish to thank the Danny Cunniff Leukemia Research Laboratory; the Gabrielle Rich Leukemia Research Foundation; the Cancer Treatment Research Foundation; the Novotny Trust; the Szydlowsky Foundation; the Figure Tree Foundation; Ronne \& Donald Hess; and the Silverstein Family for their continuous support of our ongoing basic and clinical research.

\section{References}

[1] Mbvundula EC, Rainsford KD, Bunning RA. Cannabinoids in pain and inflammation. Inflammopharmacology 2004;12: 99-114.

[2] Klein TW, Newton C, Friedman H. Cannabinoid receptors and immunity. Immunol Today 1998;19:373-381.

[3] Howlett AC. The cannabinoid receptors. Prostaglandins Other Lipid Mediat 2002;68-69:619-631.

[4] Newton CA, Klein TW, Friedman H. Secondary immunity to Legionella pneumophila and Th1 activity are suppressed by delta-9-tetrahydrocannabinol injection. Infect Immun 1994;62:4015-4020.

[5] Klein TW, Newton CA, Nakachi N, Friedman H. Delta 9tetrahydrocannabinol treatment suppresses immunity and early IFN- $\gamma$, IL-12, and IL-12 receptor beta 2 responses to Legionella pneumophila infection. J Immunol 2000; 164:6461-6466.

[6] Zhu LX, Sharma S, Stolina M, et al. Delta-9-tetrahydrocannabinol inhibits antitumor immunity by a CB2 receptormediated, cytokine-dependent pathway. J Immunol 2000; 165:373-380.

[7] Yuan M, Kiertscher SM, Cheng Q, Zoumalan R, Tashkin DP, Roth MD. Delta 9-Tetrahydrocannabinol regulates Th1/Th2 cytokine balance in activated human T-cells. J Neuroimmunol 2002;133:124-131.

[8] Munro S, Thomas KL, Abu-Shaar M. Molecular characterization of a peripheral receptor for cannabinoids. Nature 1993;365:61-65.

[9] Thomas BF, Gilliam AF, Burch DF, Roche MJ, Seltzman HH. Comparative receptor binding analyses of cannabinoid agonists and antagonists. J Pharmacol Exp Ther 1998; 285:285-292.

[10] Cunha JM, Carlini EA, Pereira AE, et al. Chronic administration of cannabidiol to healthy volunteers and epileptic patients. Pharmacology 1980;21:175-185.

[11] Consroe P, Laguna J, Allender J, et al. Controlled clinical trial of cannabidiol in Huntington's disease. Pharmacol Biochem Behav 1991;40:701-708.
[12] Watzl B, Scuderi P, Watson RR. Influence of marijuana components (THC and CBD) on human mononuclear cell cytokine secretion in vitro. Adv Exp Med Biol 1991;288:63-70.

[13] Malfait AM, Gallily R, Sumariwalla PF, et al. The nonpsychoactive cannabis constituent cannabidiol is an oral anti-arthritic therapeutic in murine collagen-induced arthritis. Proc Natl Acad Sci USA 2000;97:9561-9566.

[14] Costa B, Colleoni M, Conti S, et al. Oral anti-inflammatory activity of cannabidiol, a non-psychoactive constituent of cannabis, in acute carrageenan-induced inflammation in the rat paw. Naunyn Schmiedebergs Arch Pharmacol 2004;369:294-299.

[15] Gaoni Y, Mechoulam R. The isolation and structure of delta1-tetrahydrocannabinol and other neutral cannabinoids from hashish. J Am Chem Soc 1971;93:217-224.

[16] Ji YH, Weiss L, Zeira M, et al. Allogeneic cell-mediated immunotherapy of leukemia with immune donor lymphocytes to upregulate antitumor effects and downregulate antihost responses. Bone Marrow Transplant 2003;32:495-504.

[17] Kikutani $\mathrm{H}$, Makino $\mathrm{S}$. The murine autoimmune diabetes model: NOD and related strains. Adv Immunol 1992; 51:285-322.

[18] Wicker LS, Todd JA, Peterson LB. Genetic control of autoimmune diabetes in the NOD mouse. Annu Rev Immunol 1995;13:179-200.

[19] Pozzilli P, Signore A, Williams AJ, Beales PE. NOD mouse colonies around the world-recent facts and figures. Immunol Today 1993;14:193-196.

[20] Yaacob NS, Kaderi MA, Norazmi MN. The expression of cytokine genes in the peritoneal macrophages and splenic CD4- and CD8-positive lymphocytes of the nonobese diabetic mice. J Clin Immunol 2004;24:177-184.

[21] Rabinovitch A, Suarez-Pinzon WL, Sorensen O, Bleackley RC, Power RF. IFN- $\gamma$ gene expression in pancreatic isletinfiltrating mononuclear cells correlates with autoimmune diabetes in nonobese diabetic mice. J Immunol 1995;154: 4874-4882.

[22] Almawi WY, Tamim H, Azar ST. Clinical review 103: T helper type 1 and 2 cytokines mediate the onset and progression of type I (insulin-dependent) diabetes. J Clin Endocrinol Metab 1999;84:1497-1502.

[23] Satoh J, Takahashi K, Nakazawa T, Sakata Y, Toyota T. [Current concept of the pathogenesis of autoimmune type 1 diabetes mellitus]. Nippon Rinsho 1999;57:528-533.

[24] Chang JC, Linarelli LG, Laxer JA, et al. Insulin-secretorygranule specific Tcell clones in human IDDM. J Autoimmun 1995;8:221-234.

[25] Gallichan WS, Balasa B, Davies JD, Sarvetnick N. Pancreatic IL-4 expression results in islet-reactive Th2 cells that inhibit diabetogenic lymphocytes in the nonobese diabetic mouse. J Immunol 1999; 163:1696-1703.

[26] Healey D, Ozegbe P, Arden S, Chandler P, Hutton J, Cooke A. In vivo activity and in vitro specificity of $\mathrm{CD} 4+\mathrm{Th} 1$ and $\mathrm{Th} 2$ cells derived from the spleens of diabetic NOD mice. J Clin Invest 1995;95:2979-2985.

[27] Bach JF, Boitard C. Experimental models of type-I diabetes. Pathol Immunopathol Res 1986;5:384-415.

[28] Bach JF. The Non Obese Diabetic (NOD) mouse, as a model of Tcell mediated autoimmune disease. C R Acad Sci III 1992;314:45-46.

[29] Greiner DL, Rossini AA, Mordes JP. Translating data from animal models into methods for preventing human autoimmune diabetes mellitus: Caveat emptor and primum non nocere. Clin Immunol 2001;100:134-143.

[30] Stiller CR, Dupre J, Gent M, et al. Effects of cyclosporine immunosuppression in insulin-dependent diabetes mellitus of recent onset. Science 1984;223:1362-1367. 
[31] Bougneres PF, Landais P, Boisson C, et al. Limited duration of remission of insulin dependency in children with recent overt type I diabetes treated with low-dose cyclosporin. Diabetes 1990;39:1264-1272.

[32] The effect of intensive treatment of diabetes on the development and progression of long-term complications in insulin-dependent diabetes mellitus. The Diabetes Control and Complications Trial Research Group. N Engl J Med 1993;329:977-986.

[33] Swain SL. T-cell subsets. Who does the polarizing? Curr Biol 1995;5:849-851.

[34] Jun HS, Santamaria P, Lim HW, Zhang ML, Yoon JW. Absolute requirement of macrophages for the development and activation of beta-cell cytotoxic CD8+T-cells in T-cell receptor transgenic NOD mice. Diabetes 1999;48:34-42.

[35] Trinchieri G. Interleukin-12 and the regulation of innate resistance and adaptive immunity. Nat Rev Immunol 2003;3:133-146.

[36] Skeen MJ, Miller MA, Shinnick TM, Ziegler HK. Regulation of murine macrophage IL-12 production. Activation of macrophages in vivo, restimulation in vitro, and modulation by other cytokines. J Immunol 1996;156:1196-1206.

[37] Ohno $\mathrm{Y}$, Aoki $\mathrm{N}$, Nishimura A. In vitro production of interleukin-1, interleukin-6, and tumor necrosis factor-alpha in insulin-dependent diabetes mellitus. J Clin Endocrinol Metab 1993;77:1072-1077.

[38] Abdel Aziz MT, Fouad HH, Mohsen GA, Mansour M, Abdel Ghaffar S. TNF- $\alpha$ and homocysteine levels in type 1 diabetes mellitus. East Mediterr Health J 2001;7:679-688.

[39] Hunger RE, Carnaud C, Garcia I, Vassalli P, Mueller C. Prevention of autoimmune diabetes mellitus in NOD mice by transgenic expression of soluble tumor necrosis factor receptor p55. Eur J Immunol 1997;27:255-261.

[40] Rabinovitch A, Suarez-Pinzon WL. Cytokines and their roles in pancreatic islet beta-cell destruction and insulin-dependent diabetes mellitus. Biochem Pharmacol 1998;55:1139-1149.
[41] Adorini L, Trembleau S. Immune deviation towards Th2 inhibits Th-1-mediated autoimmune diabetes. Biochem Soc Trans 1997;25:625-629.

[42] Liblau RS, Singer SM, McDevitt HO. Th1 and Th2 $\mathrm{CD} 4+\mathrm{Tcells}$ in the pathogenesis of organ-specific autoimmune diseases. Immunol Today 1995;16:34-38.

[43] Rapoport MJ, Jaramillo A, Zipris D, et al. Interleukin 4 reverses T-cell proliferative unresponsiveness and prevents the onset of diabetes in nonobese diabetic mice. J Exp Med 1993;178:87-99.

[44] Cameron MJ, Arreaza GA, Zucker P, et al. IL-4 prevents insulitis and insulin-dependent diabetes mellitus in nonobese diabetic mice by potentiation of regulatory $\mathrm{T}$ helper- 2 cell function. J Immunol 1997;159:4686-4692.

[45] Tominaga $Y$, Nagata $M$, Yasuda $H$, et al. Administration of IL-4 prevents autoimmune diabetes but enhances pancreatic insulitis in NOD mice. Clin Immunol Immunopathol 1998;86:209-218.

[46] Mueller R, Krahl T, Sarvetnick N. Pancreatic expression of interleukin-4 abrogates insulitis and autoimmune diabetes in nonobese diabetic (NOD) mice. J Exp Med 1996;184:1093-1099.

[47] Rabinovitch A, Suarez-Pinzon WL, Sorensen O, Bleackley RC, Power RF, Rajotte RV. Combined therapy with interleukin- 4 and interleukin-10 inhibits autoimmune diabetes recurrence in syngeneic islet-transplanted nonobese diabetic mice. Analysis of cytokine mRNA expression in the graft. Transplantation 1995;60:368-374.

[48] Kolb H. Benign versus destructive insulitis. Diabetes Metab Rev 1997;13:139-146.

[49] Kaufman DL, Clare-Salzler M, Tian J, et al. Spontaneous loss of T-cell tolerance to glutamic acid decarboxylase in murine insulin-dependent diabetes. Nature 1993;366:69-72.

[50] Tian J, Chau C, Kaufman DL. Insulin selectively primes Th2 responses and induces regulatory tolerance to insulin in pre-diabetic mice. Diabetologia 1998;41:237-240. 